\title{
De «la teoría de la justicia» al «liberalismo político»: John Rawls y el fracaso de la justicia procedimental
}

Eduardo Hernando Nieto

\section{Introducción}

La idea fundamental de este ensayo no es otra que la de señalar claramente los cambios esenciales habidos en la filosofia rawlsiana y que han resultado en el desarrollo de una nueva teoría que pese a no ser reconocida por el autor como un cambio relevante no deja de ser catalogada por sus críticos como un explícito reconocimiento por parte del profesor de Harvard del fracaso de su proyecto inicial.

Sin embargo, el centro de nuestra atención no solamente estará focalizada en esta transición, sino que trataremos de demostrar con nuestros propios argumentos los motivos por los cuales pensamos que este proyecto de Justicia Procedimental estaba condenado a fracasar desde un inicio y que su poco afortunado fin estaba previsto desde su misma gestación. Al hacer esto, tendremos que señalar igualmente -a despecho de quienes aún se sienten ligados a él-que el formalismo jurídico del cual abreva Rawls no ha contribuido en nada en el mejoramiento de la vida humana y que, al contrario, su continua invocación durante esta modernidad al parecer ya perimida (por lo menos desde el punto de vista de la teoría) sólo ha servido para desacreditar a las instituciones jurídicas y para acrecentar la desconfianza cierta y razonable hacia la administración de Justicia.

Nadie puede dudar que el trabajo inicial del profesor Rawls levantó una gran polvareda que agitó las hasta ese entonces aletargadas aguas de la filosofia del derecho y de la teoría polítical. Aun más, cuando aparece La Teoría de la Justicia el positivismo y la filosofía analítica-dentro del 
terreno jurídico- y el conductismo -en el campo de la ciencia políticaeran definitivamente las «ciencias» hegemónicas aunque ciertamente era una verdad de perogrullo el afirmar que ambas habían contribuido de gran manera a la marginación del debate sustantivo perdido en los pliegues de la rigurosidad matemática del formalismo y de la lógica jurídica y en la abstracción de propuestas que nos conducían por laberintos sin salida.

En un intento por acabar con esta situación La Teoría de la Justicia se alzaba como una propuesta teórica que resucitaba nuevamente un concepto ya olvidado por el derecho y la política, a saber, LA JUSTI$C I A$ y de este modo recuperaba de manera honesta la preocupación por los aspectos axiológicos o valorativos presentes desde siempre en la filosofía del derecho y en la filosofia política.

Sin embargo (y esto lo observaremos a lo largo de este ensayo), su aproximación sustantiva terminaría por caer irremediablemente dentro del formalismo que él mismo intentaba criticar y superar. Esto se debió en última medida al hecho de que las fuentes que utilizaba Rawls para su propósito fueron exactamente las mismas que usaron quienes ocasionaron toda esta crisis que mencionamos, es decir, que su proyecto aspiraba a combatir al fuego con el fuego, o lo que es lo mismo al formalismo con un nuevo formalismo aunque revestido esta vez de algunos ropajes sustantivos que contribuirán finalmente a demostrar con mayor razón las incoherencias y contradicciones del planteamiento Rawlsiano.

\section{El proyecto rawlsiano : la justicia como equidad}

Como mencionaba atinadamente un filósofo político canadiense bastante de moda en los últimos años, el proyecto de Rawls podía resumirse en una frase muy corta, a saber : la búsqueda de la igualdad liberal. ${ }^{2}$

Así pues, y como lo expresaba directamente al inicio de La Teoría de la Justicia ${ }^{3}$, Rawls esbozaba una teoría que debía estar fundamentada en base al concepto de justicia "como primera virtud de las instituciones

Human Science, editado por Quentin SkINntR, (Cambridge: Cambridge University Press, 1985), pp.101-119.

2 Nos referimos a Will Kymlicka, en Contemporary Political Philosophy, An Introduction, (Oxford: Clarendon Press, 1990), pp.50-76. También se puede ver del mismo autor, Liberalism, Community and Culture, (Oxford : Oxford University Press, 1989)

A Theory of Justice, (Oxford : Oxford University Press, 1971) 
sociales ${ }^{4}$ y que de acuerdo a la tradición anglosajona tenía que estar a su vez sustentada exclusivamente en derechos, teniendo en consideración además la importancia de la Corte Suprema dentro de la política norteamericana y la posibilidad de apelar a derechos que se encuentran en su Constitución. ${ }^{5}$

En este sentido, es evidente que se trataba de una teoría moralmente individualista:

«Supongamos, para fijar las ideas, que una sociedad es una asociación más o menos autosuficiente de personas que en sus relaciones reconocen ciertas reglas de conducta que reconocen como obligatorias y que en su mayoría actúan de acuerdo con ellas. Supongamos además que estas reglas especifican un sistema de cooperación planeado para promover el bien de aquellos que toman parte en él.» ${ }^{6}$

Sin embargo, esta visión individualista tendría dos vertientes, una primera acentuaría el aspecto metafísico señalando a los hombres como agentes de su destino y los operadores de la vida social no estando sometidos a ninguna fuerza externa que los dirija. Toda dependencia de un hombre hacia otro sería meramente contingente. La segunda vertiente, esto es, el individualismo moral señalaría que son solamente los hombres quienes diseñan las instituciones socio-políticas y que solo debemos de tomar en cuenta su interés particular para tomar tales acuerdos. Ahora bien, si bien nadie puede dudar de que las instituciones sociales $y$ políticas van a ser construídas en favor del individuo y no para ninguna comunidad específica o para una cultura en particular (siendo así una propuesta moral individualista), la teoría rawlsiana podría descartar de su

Edición en espanool : La Teoría de la Justicia (México : Fondo de Cultura Económica, 1995, segunda edición)

"Cada persona posee una inviolabilidad fundada en la justicia que ni siquiera el bienestar de la sociedad en conjunto puede atropellar. Es por esta razón por la que la justicia niega que la pérdida de libertad para algunos se vuelva justa por el hecho de que un mayor bien es compartido por otros. No permite que los sacrificios impuestos a unos sean compensados por la mayor cantidad de ventajas disfrutados por muchos. Por tanto, en una sociedad justa, las libertades de la igualdad de ciudadanía se dan por establecidas definitivamente; los derechos asegurados por la justicia no están sujetos a regateos políticos ni al cálculo de intereses sociales.»pp.17-18.

\footnotetext{
$4 \quad$ Ibid.

5 Ryan, Alan, Op. cit. p.104.

^ Rawls, John, Op. cit.., p.18.
} 
interior la visión metafísica si es que lograse demostrar que las relaciones que desea mantener no serían contingentes sino más bien duraderas.?

La sociedad para Rawls implicaba la comunión entre intereses particulares pues ésta hacía que se puedan satisfacer deseos que de otro modo no serían posible de lograr; empero, existirían al mismo tiempo conflictos de intereses pues usualmente las personas tienen diferencias en torno al modo como se deben de distribuir los beneficios que se logran dentro de la sociedad, es en este sentido que Rawls señalaba la urgencia por contar con uun conjunto de principios para escoger entre las diferentes disposiciones sociales que determinan esta división de ventajas y para suscribir un convenio sobre las participaciones distributivas correctas. Estos principios son los principios de la justicia social: proporcionan un modo para asignar los derechos y deberes en las instituciones básicas de la sociedad y definen la distribución apropiada de los beneficios y las cargas de la cooperación social». ${ }^{8}$

El fin entonces de su trabajo era hallar lo que él denominaba una Well ordered society (una sociedad bien ordenada) que no solamente se circunscribiría a procurar el bien de sus miembros sino que debía de estar regulada por una concepción pública de la justicia que contuviese las siguientes características: a) que todos acepten los mismos principios de justicia, b) que las instituciones sociales satisfagan estos principios. ${ }^{9}$ Así pues, "puede pensarse que una concepción pública de la justicia constituye el rasgo fundamental de una asociación humana bien ordenada. ${ }^{10}$

Evidentemente, una sociedad bien ordenada no era algo que pudiéramos hallar a la vuelta de la esquina como el mismo Rawls lo admitía. De hecho, las desavenencias en torno a lo que deben de ser las concepciones de justicia varían de una persona a otra, empero lo que si es algo real es el hecho de que todos nosotros tenemos una noción de lo que significa lo justo, o sea de reconocer la necesidad de contar con un nú-

7 Kukathas, Chandran \& Rawls, Philip Pettit, $A$ theory of Justice and its Critics (Cambridge: Polity Press, 1990), pp.10-11.

De hecho, van a ser los autores comunitaristas quienes señalarán a La teoría de la Justicia, como una teoría que se basa también en el individualismo metafísico.

* Raws, John, Op. cit.

$9 \quad$ Ibid.

Por cierto, que el tema de la sociedad bien ordenada tiene un mayor desarrollo en la tercera parte de La Teoria de la Justicia, Capítulo VIII, El sentido de la Justicia, pp. 410-417.

10) Ibid., p. 19 
mero de principios que asignen derechos y deberes básicos y de establecer las cargas y exoneraciones de la cooperación social. ${ }^{11}$

En síntesis, Rawls proponía que el objeto primario de la Justicia era la estructura básica de la sociedad, esto es, la manera como las instituciones sociales distribuían los derechos y los deberes fundamentales y establecían la división de las ventajas que producía el trabajo cooperativo dentro de la sociedad. ${ }^{12}$

Ahora bien, por instituciones sociales el profesor de Harvard entendía «la constitución política y las principales disposiciones económicas y sociales. Así, la protección jurídica de la libertad de pensamiento y de conciencia, la competencia mercantil, la propiedad privada de los medios de producción y la familia monógama son ejemplos de las grandes instituciones sociales. Tomadas en conjunto, como esquema, las grandes instituciones definen los derechos y los deberes e influyen sobre sus perspectivas de vida, sobre lo que puede esperar hacer y sobre lo que haga». ${ }^{13}$

Siguiendo esta perspectiva de análisis Rawls intentaba fundar una teoría que recurriese a la generalización y a la abstracción de las recordadas teorías contractualistas de los siglos XVII y XVIII (verbigracia, Locke, Rousseau y Kant), pero pensándose ya no como un contrato que buscase conformar una sociedad o una determinada forma de gobierno, sino que se concretase a la selección de los principios de justicia para conformar la estructura básica de la sociedad. ${ }^{14}$

Así pues se pretendía escoger los principios "que las personas libres y racionales interesadas en promover sus propios intereses aceptarían en una posición de igualdad como definitorios de los términos fundamentales de su asociación. Estos principios han de regular todos los acuerdos posteriores; especifican los tipos de cooperación social que se puedan llevar a cabo y las formas de gobierno que pueden establecerse. A este modo de considerar lo llamaré justicia como imparcialidad» ${ }^{15}$

Pero antes de entrar de lleno en la propuesta rawlsiana y su neocontractualismo vale la pena echar una ligera ojeada a dos de las "teorías de justicia” que hasta antes de la publicación de su libro eran hegemónicas y cuyas limitaciones de alguna manera le sirvieron de pretexto para intentar superarlas vía el desarrollo de su propia propuesta. ${ }^{16}$

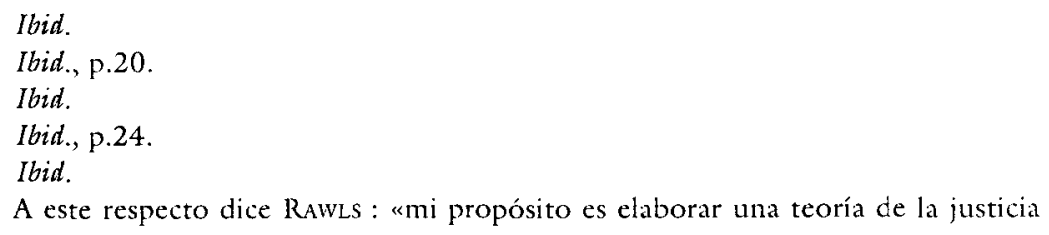


Este paréntesis nos facilitará entonces la comprensión del contexto y el sentido que tomará La teoría de la Justicia para poder entrar más adelante al estudio más profundo de su obra.

Ciertamente, el objetivo de Rawls no era otro que el de «combatir y superar la debilidad teórica de la filosofía moral predominante en el mundo anglosajón, el utilitarismo, sin por ello caer en los brazos del intuicionismo, al parecer la única alternativa teórica a la propuesta anterior ${ }^{17}$, y como se señalaba también este proyecto tenía que concluir en una teoría deontológica que otorgase la prioridad al deber (right) sobre el bien $(g o o d)$ siendo el resultado de esto una teoría que nos recordase fundamentalmente al constructivismo kantiano antes que a cualquier otro tipo de aproximación filosófica. ${ }^{18}$

Como acabamos de mencionar, las dos grandes propuestas morales desde fines del siglo XIX y buena parte del XX la constituían las corrientes utilitaristas e intuicionistas.

En el caso del utilitarismo clásico se dice que era la concepción de justicia más racional, pues de lo que se trataba era de incrementar nuestros beneficios y limitar nuestros perjuicios en base a una reflexión que apuntaba ciertamente a la realización de la felicidad individual que era de alguna manera el brasero que servía para identificar el concepto beneficio. Teniendo en cuenta la influencia de las ciencias modernas y la utilización de las matemáticas, el utilitarismo marchaba conjuntamente dentro de una visión cuantitativa de la realidad de allí entonces su énfasis en el concepto del incremento de la felicidad. Ahora bien, así como un sujeto era capaz de equilibrar ganancias presentes y futuras, esto es, organizar su bienestar, esto mismo, -decían los utilitaristas- cra capaz de realizar una sociedad. La sociedad podía equilibrar entonces los beneficios y los perjuicios entre personas diferentes.

Desde este punto de vista se iba a entender que la justicia social era

que represente una alternativa al pensamiento utilitario en general $y$, por tanto, a todas sus diferentes versiones. Creo que, en esencia, el contraste entre el punto de vista contractual y el utilitario sigue siendo el mismo en todos estos casos. En consecuencia, compararé la justicia como imparcialidad con variantes familiares del intuicionismo, perfeccionismo y utilitarismo, con objeto de mostrar, del modo más simple, las diferencias subyacentes.»Ibid., p.34.

17 CAmps, Victoria, Introducción al trabajo de John Rawls Sobre las Libertades, (Barcelona : Paidos, 1990), p. 10.

\section{:s Ibid.}

Ver también de Santiago Nino, Carlos, Ética y Derechos Humanos, (Buenos Aires : Astrea, 1989), Cap. III y de John Rawls, "Kantian Contructivism in Moral Theory", en The Journal of Philosophy, setiembre 1980, vol LXXVII, No. 9 
la maximización del bienestar de un grupo determinado de personas y esto por cierto era algo que no podía levantar ninguna crítica razonable.

Empero, el utilitarismo distaba mucho de ser la panacea que pretendía, y las primeras voces críticas provenían desde distintas vertientes, sea desde una posición moral pagana o cristiana en donde el actuar de tal o cual manera para satisfacer exclusivamente un interés individual era algo inaceptable pues quedaban descartados de hecho los conceptos de ethos y de caritas $^{19}$, sea desde una posición más racional y liberal -y será desde aquí de donde se desencadenará la crítica rawlsiana- esto básicamente cuando continuando con el análisis del utilitarismo encontrábamos que éste era a su vez una teoría teleológica en donde «el bien era definido independientemente de lo justo ${ }^{20}$ (entendiendo por cierto lo justo right-como lo justo formal) siendo lo justo aquello que maximizaba el bien. Comenzando entonces de la definición de un único bien o fin como el de la felicidad tendríamos que podríamos jerarquizar los placeres sin tener que recurrir al concepto de lo justo y esto traería como problemas por ejemplo el imponer al resto de personas ideas particulares sobre el bien, en otras palabras, podíamos caer en el peligroso juego de socavar el principio moderno de igualdad que subyacía dentro de la ideología moderna y que era justamente su propio sustento. ${ }^{21}$

19 Pensamos por ejemplo en las conductas de los paganos quienes actuaban inspirados siempre por el deseo de inmortalidad que se veía reflejado en actividades tan específicas como los juegos olímpicos, o en los comportamientos de los cristianos quienes anhelando reencontrase con Dios practicaban la caridad y el altruismo como norma de vida.

20) Rawls, John, Ibid., p.36.

Más adelante Rawls afirmará que "las estructuras de las doctrinas teleológicas es radicalmente equívoca : ya desde un principio relacionan erróneamente lo justo y lo bueno. No intentaremos dar forma a nuestra vida atendiendo primero al bien, independientemente definido. No es nuestro propósito el de revelar principalmente nuestra naturaleza, sino más bien los principios que admitiriamos que gobernasen las condiciones básicas en que han de formarse estos propósitos y la manera en que deben de perseguirse. Porque el yo es anterior a los fines que por él se afirman; incluso un fin dominante tiene que ser elegido entre muchas posibilidades. No hay modo de sobrepasar la racionalidad deliberativa. Invertiríamos, pues, la relación entre lo justo y lo bueno propuesta por las doctrinas teleológicas y consideraríamos lo justo como prioritario. La teoría moral se desarrolla, entonces, actuando en sentido contrario.»

Ibid., p. 506.

Vale la pena añadir que otra corriente teleológica que no es mencionada directamente pero que marco el rumbo de la política y el derecho cristiano fue el tomismo y la doctrina del derecho natural.

21 Sin embargo, vale la pena señalar que el utilitarismo fue la corriente que hizo 
La teleología implicaba contar con un fundamento axiológico que era el que articulaba el resto de conceptos y este fundamento tenía que ser aceptado por todos. Sin embargo, las filosofias políticas y la filosofias del derecho modernas partían del hecho de negar cualquier verdad pues si asumíamos algún concepto desde esta perspectiva caíamos en el peligro de ultrajar la libertad e independencia de quienes no compartieran con nosotros dicha verdad. Quedaba entonces muy claro que por más que la felicidad pudiese ser algo que nadie aparentemente podría rechazar, el modo de entenderla podía ser muy variado. :Acaso no existían personas que pudieran sentirse felices a través del dolor? Esto en psicología posee por cierto un nombre: masoquismo.

Pero, donde el utilitarismo comenzaba a padecer de problemas más concretos era el caso de que al maximizarse el concepto de felicidad podía producir la desdicha de otros, o inclusive la desdicha de todos o su felicidad efimera.

Si tuviéramos 100 soles para repartirlo entre un grupo de ancianos y quisiéramos usar el principio utilitarista, podríamos llegar a la conclusión que deberíamos de repartir 100 bolsitas de té entre 100 ancianos. Evidentemente cada bolsita duraría apenas una semana cuando mucho, ¿no sería mejor comprar 10 frazadas para beneficiar a 10 ancianos, considerando que este bien no se consumiría fácilmente y podría inclusive ser usado por distintas personas? o yéndonos a ejemplos extremos pero no por ello menos reales jacaso el famoso circo romano con los esclavos esperando a los leones, no satisfacía el ideal utilitario de la gran masa que disfrutaba de tal espectáculo?. Definitivamente sí, este era el gran padecimiento de esta filosofía moral, aun más el utilitarismo en buena cuenta escamoteaba las disquisiciones sustantivas por la simplicidad y el formalismo de su principio fundamental ${ }^{22}$ y por ende violaba sistemáticamente el principio de la autonomía y la libertad individual.

Es en este sentido que aparecía entonces el intuicionismo como una alternativa moral que si bien era cercana al utilitarismo tenía otras variables. «El intuicionismo dice que existen muchos principios que guían

\footnotetext{
desarrollar al Derecho penal al colocar las sanciones penales como un remedio que tendería a disminuir el crimen, esto es, que si bien es cierto un delincuente podría beneficiarse de su ación la pena que le esperase sopesada con el beneficio que podría obtener le haría inclinar la balanza -esto pensando de modo racional-por evitar el crimen.

Ver de D.D Raphali, Moral Philosphy, (Oxford : Oxford University Press, 1985), p.41.

22 El Utilitarismo es la doctrina que apunta a la maximización de la felicidad por el mayor número de personas.
} 
una correcta conducta humana, cada uno de estos principios sirve como standard o criterio de una clase adecuada de actos correctos o deberes. Dichos principios -éste mantiene-, son evidentes per-se, y se los reconoce como verdaderos por proceder de una intuición racional $»^{23}$.

Así pues, se podía tener una lista de principios que deberían de ser evidentes y entre estos principios que seleccionaba el intuicionismo podíamos encontrar :

«a) el promover la felicidad de otras personas

b) el evitar dañar a los demás

c) el tratar justamente a las personas que podría ser de acuerdo a su mérito, a su igualdad o a su necesidad

d) decir la verdad

e) mantener nuestras promesas

f) mostrando gratitud

g) promoviendo nuestra propia felicidad (prudencia)

h) manteniendo y promoviendo nuestras virtudes». ${ }^{24}$

Vemos a primera vista que el primer principio intuicionista coincidía con el principio fundante del utilitarismo y, por ende, este principio caería bajo las mismas críticas que le cabiesen al utilitarismo quedando descartado de plano. Sin embargo, no era necesario analizar rigurosamente cada uno de los principios para saber que el intuicionismo tenía tantos problemas como el utilitarismo. En primer lugar, los famosos principios evidentes para cualquier mortal en la práctica no parecían ser tales pues lo que si era muy evidente era el hecho de que todos los principios destacaban por su poca claridad lo que justificaba la aparición de distintas corrientes intuicionistas que defendían un principio en favor del otro. En segundo lugar, y esto era quizás lo más grave, la existencia de tal pluralidad de principios no podía terminar en otra cosa que no fuera un conflicto entre ellos. Por ejemplo como atinadamente señalaba el profesor Raphael, «uno podía encontrar una situación en la cual uno podía cumplir con una promesa solamente a expensas de sacrificar alguna felicidad (sea la tuya o la de los demás), o puedes encontrar que das una respuesta honesta a expensas de quebrar una promesa de confidencia». ${ }^{25}$ ¿Cómo se podría arbitrar entre principios tan opuestos? El gran problema era que no había manera de arbitrar tal conflicto y esto hacía

\footnotetext{
23. RAPHAF, D.D., Ibid, p.43.

$24 \quad$ Ibid., p.44.

$25 \quad$ Ibid., p. 45.
} 
inviable al intuicionismo como una filosofía moral valedera y capaz de satisfacer los intereses individuales.

Una vez comprobadas las limitaciones de ambas y compartiendo ciertamente las objeciones que señalan tanto Rawls como Raphael conviene acercarnos ahora hacia los postulados centrales de la teoría de la justicia a fín de que analicemos el modo como el profesor de Harvard intentó construir una teoría que superase con creces las limitaciones de las corrientes utilitaria e intuicionista (la teleología) ${ }^{26}$ y permitiese así contar con una teoría de la justicia que sin dejar de ser neutral pudiese establecer ciertos parámetros de sustantividad. (éase equidad)

Rawls a través de un razonamiento fino pero al mismo tiempo bastante abstracto utilizará como primer recurso la teoría contractualista que le permitirá plantear una tesis de lo deseable ${ }^{27}$ en cuanto a lo que sería lo más adecuado pactar en una situación hipotética que a semejanza del estado de naturaleza iusnaturalista plantearía a los seres humanos racionales y libres ${ }^{28}$ en una condición de igualdad. Este punto de partida va a ser llamado por el profesor Rawls como la posición original:

«En la justicia como imparcialidad, la posición original de igualdad corresponde al estado de naturaleza en la teoría tradicional del contrato social. Por supuesto que la posición original no está pensada como un estado de cosas históricamente real, y mucho menos como una situación primitiva de la cultura. Se considera como una situación puramente hipotética caracterizada de tal modo que conduce a cierta concepción de la justicia. Entre los

\footnotetext{
26 En realidad como señala Micharl SANDll «en la visión de Rawls, la teleología confunde la relación de lo justo con lo bueno porque malinterpreta la relación del Yo y sus fines. Esto conduce a Rawls a expresar otra prioridad deontológica. Al contrario de la Teleología, él señala que lo que es más importante para nosotros no son los fines que escogemos sino la capacidad que tengamos de elegirlos. Y esta capacidad está localizada en el yo consciente que debe de ser anterior a los fines que escoja."

Michael SANDEL, Liberalism and the Limits of Justice (Cambridge : Cambridge University Press, 1982), p.19.

27 De hecho, los defensores de la teoría de la Justicia han hecho hincapié en dos características fundamentales para apoyar esta propuesta. Se dice así, que la teoría de Rawls es una tesis que apunta tanto a lo deseable como a lo posible, esto es, que intenta ser normativa y descriptiva al mismo tiempo. Por lo tanto, no escamotearía lo ideal -lo deseable-como tampoco caería en la ilusión de las utopías políticas (de allí el talante láctico).
}

Chandran Kukathas \& Philip Pettit., Op. cit., pp. 6-11.

Rawls, John, Ibid., pp. 24-25. 
rasgos esenciales de esta situación, está el que nadie sabe cuál es su lugar en la sociedad, su posición, clase o status social; nadie sabe tampoco cuál es su suerte en la distribución de ventajas y capacidades naturales, su inteligencia, su fortaleza, etc. Supondré, incluso, que los propios miembros del grupo no conocen sus concepciones acerca del bien, ni sus tendencias psicológicas especiales. Los principios de la justicia se escogen tras un velo de ignorancia. Esto asegura que los resultados del azar natural o de las contingencias de las circunstancias sociales no darán a nadie ventajas ni desventajas al escoger los principios. Dados que todos están situados de manera semejante y que ninguno es capaz de delinear principios que favorezcan su condición particular, los principios de la justicia serán el resultado de un acuerdo o un convenio justo, pues dadas las circunstancias de la posición original y la simetría de las relaciones entre las partes, esta situación inicial es equitativa entre las personas en tanto que seres morales, esto es, en tanto que seres racionales con sus propios fines, a quienes supondré capaces de un sentido de la justicia. Podría decirse que la posición original es el statu quo inicial apropiado y que, en consecuencia los acuerdos fundamentales logrados en ella son justos..2\%

El velo de ignorancia como dice el mismo Rawls apuntará a utilizar la noción de justicia puramente procesal como sustento de su teoría ${ }^{30}$ Esto tiende a eliminar los efectos de las diferencias y las contingencias de la $v^{\text {vida }}{ }^{31}$, se podría decir entonces que la idea general es que las distribuciones de los bienes sociales serían justos si fueran un resultado de la aplicación de principios que fueran neutrales según los diferentes ideales, propósitos y planes de vida; y ellos serían neutrales si (y porque) ellos fueran escogidos por individuos en una posición adecuada de inocencia acerca de nuestros deseos, capacidades, y posición social.

«La posición originaria sería la idea mediadora entre una determinada forma de concebirnos a nosotros mismos y ciertos princi-

\footnotetext{
29. Ibid., p.25.

30) Ibid., p. 135.

3ı Como afirma el mismo Rawls este artilugio del velo de ignorancia es un «recurso" que esta implícito en los trabajos de Kant particularmente en la estructuración de su imperativo categórico pues esta ley universal no tiene en cuenta el lugar que ocupamos en la sociedad.

Ibid.
} 
pios de justicia: detrás de esta idea están las ideas kantianas de autonomía y razón práctica» ${ }^{32}$.

Para explicarlo de manera más sencilla Rawls se plantea el modo de resolver dos inquietudes, la primera versa sobre las cuestiones básicas de la sociedad y la segunda sobre las reglas que proporcionarían los fundamentos de una sociedad justa, para hallar estas respuestas deberíamos hacer lo siguiente: debemos suponer la existencia de un congreso de hombres y mujeres que todavía no pertenecen a ninguna sociedad determinada y que se han juntado en una suerte de asamblea constitucional que establecerá las reglas esenciales de la comunidad que van a formar. Dichas personas no son ciertamente marcianos sino que tienen cualidades específicas, deseos concretos y son identificables, sin embargo atraviesan por una suerte de olvido o amnesia (velo de ignorancia) que no les permite recordar quienes son, no saben si son pobres o ricos, feos o atractivos, blancos u orientales, talentosos o brutos y lo más importante desconocen sus propias creencias en torno a lo que puede ser valioso en la vida. Ciertamente todos poseen ideas en relación a lo que sería su vida, sus preferencias morales etc., pero el problema es que nadie sabe cuales serían realmente sus verdaderas opiniones sobre estos temas vitales. Pero a pesar de esta situación ellos deben de estar en capacidad de ponerse de acuerdo sobre lo que debería ser su constitución política. Ahora bien como seres racionales Rawls indica que tendrían que llegar a acuerdos de justicia. ${ }^{33}$ Dichos acuerdos configurarían los dos principios de justicia de la teoría rawlsiana :

1. «Primero: Cada persona ha de tener un derecho igual al más extenso sistema total de libertades básicas compatible con un sistema similar de libertad para todos.

2. Segundo: Las desigualdades económicas y sociales han de estructurarse de manera que sean para:

32 Beltrán Pedreira, Elena, "El Neoliberalismo: La Filosofía politica de Jobn Rawls», en Fernando Vellespin editor, Historia de la Teoría Política, Vol. 6 (Madrid: Alianza, 1995), p. 113.

3.3 Esta explicación con términos muy elementales la hemos extraído en gran parte de la entrevista «Filosofía y Política» que concedió el Profesor de Jurisprudencia de la Universidad de Oxford, Ronald Dworkin al periodista británico Bryan Magee. Bryan Magee, Los Hombres detrás de las Ideas, algunos creadores de la filosofía contemporánea (México : Fondo de Cultura Económica, 1993, segunda reimpresión), pp.254-276. 
a) mayor beneficio de los menos aventajados, de acuerdo con un principio de ahorro justo, y

b) unidos a los cargos y las funciones asequibles a todos, en condiciones de justa igualdad de oportunidades $»^{34}$.

Sin embargo, estos dos principios poseen como dice Rawls un orden lexicográfico, es decir que el primer principio (el de la libertad) debe tener prioridad sobre el segundo (el de la justicia). Esta ordenación significa que cualquier violación a las libertades básicas iguales protegidas por el primer principio no pueden ser justificadas por mayores ventajas sociales y económicas. Una libertad solo puede ser limitada por otra ${ }^{35}$ Asimismo Rawls señala que las libertades básicas del primer principio estarían comprendidas por la libertad política (el derecho a votar y ser elegibles para ocupar puestos públicos) y la libertad de expresión y la libertad de reunión; la libertad de conciencia y de pensamiento; la libertad de la persona que incluye la libertad frente a la opresión psicológica, la agresión física y el desmembramiento (integridad de la persona); el derecho a la propiedad personal y la libertad respecto al arresto y detención arbitrarios, tal y como está definido por el concepto de estado de derecho. Estas libertades habrán de ser iguales conforme al primer principio. ${ }^{36}$

El orden lexicográfico por cierto, también se utiliza en el ségundo principio aunque de manera inversa, esto es, que la igualdad de oportunidades b) se antepone al denominado principio de la diferencia a). Este segundo principio establece además la prioridad de la justicia sobre la eficiencia y el bienestar es decir que se impone al «principio de la eficiencia», y la idea de maximizar la suma de ventajas en la sociedad. ${ }^{37}$

Ahora bien, por más tentadores que apareciesen ambos principios, las críticas no se harían esperar y así por ejemplo el primer principio de las libertades básicas enfrentó desde un inicio grandes críticas, como las del profesor H.L.A Hart, en la medida en que no se explicaba con claridad

\footnotetext{
34 RAwLs, John, TJ, Ibid., p.280.

35 Lo cual significa que las libertades no son absolutas sino que se autolimitan. De hecho el mismo Rawls menciona que «dado que las diferentes libertades básicas están abocadas a entrar en conflicto, las reglas institucionales que definen estas libertades deben de ajustarse de forma que encajen en un esquema de libertades coherente. "John Rawls, Sobre las Libertades, Ibid., p.37.

Ahora bien, el hecho de que esto se realice de manera armónica, esto es otra historia, al respecto se puede ver de Eduardo HiRnando NieTo, “¿Existen los Derechos Naturales», en: DERECHO-PUC, No. 49 , Dic.95.

36 Ibid., p.68.

37 Kukathas \& Petit, Ibid., p.44.
} 
en la TJ las razones por las cuales las personas en la posición original tendrían que elegir estas libertades básicas; y porque su prioridad ni tampoco Rawls expresaba el modo como podrían especificarse y adaptarse las libertades en las etapas constitucional, legislativa y judicial una vez que se desvele el velo. ${ }^{38}$ En este sentido, Rawls aclarará que no estaba haciendo alusión a la libertad en abstracto y para corroborar lo dicho, cambiará algunos de los términos que utiliza en su primer principio, y así ya no hablará más del «más amplio sistema total de libertades...»39 sino de «un régimen plenamente suficiente de libertades... ${ }^{40}$ que van a ser tipificadas con más detalle en el ensayo citado y que de alguna manera responden ya no a una visión metafísica y trascendente como la perspectiva kantiana de la teoría de la Justicia sino a una visión más bien contextualizada y que respondía sin hesitar a la realidad democrática de Norteamérica. ${ }^{41}$

Pero antes de entrar con mayor detalle a las críticas sustantivas a la propuesta del profesor de Harvard, debemos llamar la atención en relación al segundo principio para decir que éste no es menos problemático que el primero. Brian Barry; en un conocido libro sobre Rawls ${ }^{42}$, mencionaba por ejemplo que el término de «las desigualdades económicas y sociales" nos dejaba en un vacío y ambigüedad enorme pues los seres humanos podían establecer múltiples maneras de exigencia sobre los recursos materiales ${ }^{43}$, Rawls hablaba de que las desigualdades son justificadas cuando favorecen a los menos aventajados de la sociedad, pero jen qué caso son justificadas las desigualdades?, ¿cuándo los más capaces toman los puestos dirigentes y así por ejemplo podrían realizar políticas sociales y económicas en beneficio de todos ?, pero ¿cómo podríamos medir el beneficio que obtendrían los menos favorecidos por estas distinciones de status?

38 HART, H.L.A, "Rawls on Liberty and its Priority" en Norman Daniels, Reading Rawls, (Nueva York: Basic Books, 1975) pp. 249-252.

Justamente en el ensayo de Rawls Sobre las Libertades, se dedicará a responder a los argumentos levantados por Hart.

3. En realidad lo que está diciendo Rawls ahora es que la libertad no es un bien cuantificable que puede inerementarse o disminuirse sino que es un bien sustantivo que puede sin embargo concretarse en alguna manera. (Ejemplo a través de la numeración de la libertades básicas)

40 Rawis, John, Sobre las Libertades...Ibid., pp. 34-35.

41 Beltrán, Elena, Ibid, p. 104.

42 Barry, Brian, La Teoría Liberal de la Justicia, (México : Fondo de Cultura Económica, 1993) 
Podríamos entonces resumir ambos principios de acuerdo a lo que el mismo Rawls afirma :

«Todos los bienes sociales primarios -libertad, igualdad de oportunidades, renta, riqueza y las bases del respeto mutuo- han de ser distribuídas de un modo igual, a menos que una distribución desigual de uno o de todos estos bienes redunde en beneficio de los menos aventajados». ${ }^{44}$

Se entiende pues, que estos principios son principios liberales que intentan garantizar la justa igualdad de oportunidades, limitando de alguna forma la acumulación excesiva de propiedades y de riqueza manteniendo además el acceso a la educación para todos. ${ }^{45}$

Pero después de conocer la naturaleza de estos principios ¿por qué tendrían que ser escogidos? Rawls encontrará que estos principios; comparativamente hablando, son superiores a las propuestas utilitarias, perfeccionistas, egoístas, etc. ${ }^{46}$ Igualmente presentan ciertas ventajas palpables porque son principios que estarían inmersos en una estrategia que se colocaría en la opción menos privilegiada detrás del velo de ignorancia. Esto significa que el sujeto rawlsiano se pone en el supuesto de que la elección que tendría que efectuar sería llevada a cabo no por él mismo sino por nuestro peor enemigo y en esas circunstancias lo que busca la TJ es elevar los mínimos a lo máximo, en otras palabras deberíamos poder elegir lo máximo de lo mínimo (criterio llamado MAXIMIN) y es precisamente esta elección la que efectuaría un hombre racional y libre porque de tocarnos el peor lugar en la jerarquía social por lo menos tendríamos asegurada las más importantes libertades.

La primera crítica que salta a la vista parece bastante obvia: ¿por qué tendríamos que ser tan timoratos y escoger según él el criterio maximin?, ‘acaso no podríamos ser los mejores dotados para elegir principios más beneficiosos y obviar por ejemplo el principio de la diferencia?, ¿no serían los principios de justicia unos obstáculos para nuestro propio desarrollo?, pues bien más o menos algunas de estas ideas están en el argumento que baraja otro famoso profesor de Harvard, llamado Robert Nozick ${ }^{47}$ que propugnaba una crítica desde la llamada Nueva

47 Nozick, Robert, Anarchy, State and Utopia, (New York: Basic Books, 1974), 
Derecha o libertarianismo. Una teoría como la elaborada por Rawls (particularmente el principio de la diferencia) significaría una continua intervención del Estado en la vida de las personas ${ }^{48}$ y esto sería sencillamente inaceptable y violatoria al derecho de propiedad que tenemos nosotros sobre nuestra propia persona, asimismo Nozick encuentra muy débil el planteamiento de la distribución de bienes que se produciría tras la posición original y la elección de los principios pues las cosas son siempre poseídas de antemano, las cosas vienen al mundo ya ligadas a las personas y poseídas por ellas. Desde el punto de vista de las concepciones históricas de la adquisición de propiedad las cosas no podrían caer como maná del cielo; esto aparentemente sería lo que acontecería con la $\mathrm{TJ}^{49}$.

En realidad, lo que vale la pena destacar de esta crítica más que la supuesta violación al derecho a poseernos a nosotros mismos (selfownership) que defienden los libertarios es la abstracción e idealidad de la posición original. Y si Nozick destacará la inevitabilidad de recurrir a la historia para plantear una teoría normativa o prescriptiva (aunque sea de tinte liberal), Rawls a pesar de bosquejar una propuesta que reúna a lo deseable y lo posible se apoyará como dijimos al inicio en un constructivismo kantiano que por esencia revertirá en un idealismo trascendente - de allí por ejemplo la universalidad del proyecto rawlsiano- y que será objeto de las más severas críticas elaboradas por el profesor Michael Sandel ${ }^{50}$ quien pondrá sobre el banquillo de los acusados en primer lugar al Sujeto que debería tomar parte de la posición original y a las debilidades teóricas de este formalismo de la Justicia que utilizará Rawls para legitimar su propuesta.

Como mencionamos de manera ligera al inicio, el liberalismo kantiano se fundamentaba en la distinción que se marcaba entre lo «jus-

edición en español. Anarquia, Estado y Utopia, (México : Fondo de Cultura Económica, 1988)

4. Ibid., p. 163

49) Ibid., p.198.

50) También profesor de la Universidad de Harvard y reconocido miembro de la corriente filosófica denominada comunitarista que se ha dedicado en los últimos años a desvirtuar uno por uno los argumentos teóricos centrales del liberalismo y el libertarianismo. Aparte del libro ya citado destacan sus ensayos "The Procedural Republic and the Unencumbered Self» en: Political Theory, 12/1 1984, y "Morality and the Liberal Ideal", en: New Republic, Mayo 7, 1984 ; la introducción al libro editado por él mismo, Liberalism and its Critics, (Oxford: Blackwell, 1984), y más recientemente su último libro Democracy's Discontent: America in Search of Public Pbilosophy, (Cambridge, Mass : Harvard University Press, 1996) 
to» (right) y lo «bueno» (good), esto es, entre la estructura de derechos y libertades, y las concepciones del bien que la gente buscaría dentro de esta estructura. ${ }^{51}$

Así pues, en la TJ «lo justo» es anterior a «lo bueno» y esto significa que los derechos en primer término no pueden ser sacrificados por la causa del bienestar general y en segundo lugar los principios de justicia que especifican estos derechos no pueden ser derivados de alguna visión de particular de un bien determinado, por ende «lo que justifica los derechos no es que ellos maximicen el bien público o promueven el bien general, sino más bien que ellos constituyen una estructura justa dentro de la cual los individuos y los grupos pueden escoger sus propios valores y fines, consistentes con una libertad similar para los otros».52

Esta justicia formal que adecua la justicia a un mero procedimiento supuestamente neutral ha sido cuestionado recientemente por la filosofia comunitarista que apelando en buena medida a las críticas que realiza Hegel a Kant señalan por ejemplo que es irrealizable además de ser un absurdo el anteponer "lo justo» a "lo bueno", o invocando a Aristóteles afirmando que nosotros no podemos establecer acuerdos políticos sin referirnos a propósitos comunes y a fines comunes, y no podemos concebir nuestra personalidad sin recurrir a nuestros roles como ciudadanos de una determinada comunidad..$^{53}$ De hecho, Rawls claramente afirmaba que el sujeto concurrente a la posición original era anterior a sus fines que eran definidos por él, en este sentido Sandel sostenía con contundencia que «la prioridad del sujeto sobre sus fines significaba que yo nunca era definido por mis metas y vínculos, sino que siempre era capaz de anteponerme a ellos e inclusive tener la posibilidad de revisarlos $»^{54}$.

Corroborando lo mencionado por Sandel, pensamos que es aquí donde comienzan a trastabillar de manera rotunda la propuesta rawlsiana pues al producirse la elaboración de la TJ y en su afán por mantener la neutralidad y la apertura ${ }^{55}$ que eran obviamente los objetivos de su teo-

Michael Sandel, Introducción a Liberalism and its critics, Ibid., p.3.

$52 \quad$ Ibid., p.4

53 Ibid., p.5

$54 \quad$ Ibid.

55. Definitivamente la neutralidad y la apertura son las dos características de las sociedades liberales contemporáneas y particularmente dentro del mundo anglosajón, como certeramente lo anunciara algunos años atrás el recordado profesor de la Universidad de Chicago Allan Bloom en un libro emblemático para el movimiento comunitario:

".... La reciente educación de la apertura ha rechazado todo esto. No presta atención a los derechos naturales o a los orígenes históricos de nuestro régimen que 
ría, Rawls construía un sujeto que no podía ser capaz de decidir sobre nada y esto por la sencilla razón de que los objetos de elección no estaban nunca flotando en el aire sino que se trataban siempre de valores, sentimientos, costumbres, etc., es decir objetos que estaban ubicados dentro de una comunidad específica y en un tiempo también determinado. Si separábamos; como lo hacía Rawls; al sujeto de sus fines (esto es a «lo justo» de «lo bueno»), no era posible ni siquiera la posibilidad de plantear al contractualismo como fórmula habida cuenta de que no era posible ningún de tipo de elección (que se entiende es la base del contrato). Ahora bien, por las mismas características de los principios a los que se llegaban tras la posición original era evidente que tenían que haber sido escogidos dentro de una tradición en particular; y dicha tradición no era otra que la tradición liberal-democrática que proponía tales principios como los correspondientes a una sociedad bien ordenada. Por lo tanto, mal podía Rawls plantear su teoría como una propuesta filosófica o metafisica que se mostrase universal y abstracta (como el imperativo categórico kantiano) cuando en realidad los valores guías (léase principios) tenían una historia y un contexto determinado. Esto finalmente despojaba a los principios de una validez planetaria al tiempo que se imponía como una crítica aún más aguda que aquellos quienes por ejemplo destacaban la arbitrariedad de los principios ${ }^{36}$ (esto es, por ejemplo porque se privilegiaba a la libertad por sobre la igualdad) y que colocaban paradójicamente a la TJ en la misma línea que el intuicionismo y su injustificado listado de derechos morales.

\section{Justicia Política y no metafísica}

Al inicio de la TJ Rawls acertaba con seguridad que la TJ era una teoría

ahora es enseñado como que se haya esencialmente quebrado .......está abierto a todos los hombres, a todas las clases de vida, a todas las ideologías. No existe otro enemigo que aquél que no se está abierto a todos. Pero cuando no hay objerivos compartidos o una visión del bien público, ¿es posible mantener un contrato social ?»

Bloom, Allan, The Closing of the American Mind (New York : Simon and Schuster, 1987), p. 27.

56 Por ejemplo el mismo Rawls señalaba que las libertades básicas no podían incluir ni el derecho a poseer los medios de producción (socialismo) ni tampoco el derecho a la libre contratación (libertarianismo), sin dar sin embargo mayores explicaciones del por quée.

Ver TJ, Ibid., p 69 . 
que estaba hecha para sujetos libres y racionales ${ }^{57}$ y que al mismo tiempo utilizaba el análisis de la teoría de la elección racional para conocer la naturaleza «racional» de los principios ${ }^{58}$. Definitivamente, el sentido del velo de ignorancia y el privilegio de lo «justo» sobre lo «racional» confirmaban esta supremacía de lo racional, es decir, de la búsqueda de la satisfacción de nuestro interés privado sobre el colectivo en base a un cálculo instrumental para medir nuestros beneficios. El velo de ignorancia servía entonces para morigerar esta característica de los seres humanos en la posición original mientras que los principios resultado del Contrato apuntaban a consolidar una sociedad bien ordenada, es decir una comunidad liberal en la cual a pesar del individualismo latente se pudiese compartir ciertas tareas de manera común. Empero, este privilegio del sujeto racional en la TJ produjo más bien una andanada de críticas que señalaban por ejemplo que el modelo rawlsiano solamente establecería una "sociedad de desconocidos» ${ }^{59}$ y quizá hasta una «sociedad de enemigos» ${ }^{61}$. La crisis moral y social de las sociedades postindustrializadas alimentaron entonces esta crítica a los modelos individualistas y racionalistas cuya decadencia se vislumbraba en buena medida como fruto del comportamiento de estos sujetos maximizadores y poco altruistas. El velo de ignorancia era una mera abstracción y la realidad distaba mucho de la idélica posición original. Al mismo tiempo, parecía también un poco contradictorio el que los sujetos racionales decidiesen contar con un principio como el de la diferencia que quizá no calzaba de manera apropiada con la racionalidad instrumental. En fin todas estas críticas motivaron un replantiamiento en la TJ que se comenzó a gestar particularmente en un ensayo publicado en 1985 y que culminaría con su obra Liberalismo Politico. ${ }^{61}$ El primer paso importante iba a

\footnotetext{
57 TJ, Ibid, , p.24.

$58 \quad$ Ibid., p. 30.

59 Esto es lo que senalaría el profesor Michael Sandel y que representaría en síntesis el pensamiento comunitarista.

60) Este sería el talante de un autor tan antiliberal como antimoderno como el profesor Carl Schmitt, ver El Concepto de lo Politico, (Madrid: Alianza, 1991) y para un análisis de algunas de sus ideas se puede revisar de Eduardo Hernando Nieto, "Carl Schmitt y los desafüos al Estado Constitucional,, en Pensamiento Constitucional, Año III, No. 3, 1996. Pontificia Universidad Católica, Lima Perú.

61 El artículo en mención se titula "Justice as Fairness : Political not Metaphysical" (Justicia como Equidad: Política no Metafísica), publicado en Philosophy and Public Affairs, 14 (Summer 1985). Empero, los grandes cambios en la TJ comienzan mucho tiempo atrás particularmente en sus conferencias llamadas "Kantian Contructivism in Moral Theory: The Dewey Lectures 1980", editadas en Journal of Philosophy, 77 (1980).
} 
ser el cuestionamiento a la racionalidad de la TJ para abrir espacio a un concepto que tenía más bien una perspectiva bastante distinta: la razonabilidad. Ésta decía el mismo Rawls aparece por ejemplo cuando «entre iguales, están dispuestos a proponer principios y normas como términos justos de cooperación y cumplir con ellos de buen grado, si se les asegura que las demás personas harán lo mismo» ${ }^{62}$.

En otras palabras, lo razonable debía formar parte inseparable de toda sociedad entendida como un sistema justo de cooperación y por ende superaría también la mediatizada visión racional en la medida que ésta poseía una sensibilidad moral que era imprescindible para consolidar una sociedad bien ordenada. ${ }^{63}$

Así pues, Rawls recula en el LP de su intención de fundar su teoría bajo los cimientos de la «teoría de la elección racional» (rational choice theory) de la economía moderna y para eso «enfatiza el hecho de que las partes en la posición original están interesadas en asegurar para la persona que representan los más altos intereses de orden con los que contamos para desarrollar y ejercitar nuestros dos poderes morales, esto es, promover nuestra determinada concepción de bien cualquiera que sea y actuar con justicia» ${ }^{64}$.

Como luego afirmara Rawls, "en la justicia como imparcialidad, lo razonable y lo racional se consideran dos ideas básicas distintas e independientes». ${ }^{65}$ Son distintas pues no es factible derivar lo razonable de lo racional y por consiguiente son ideas autónomas aunque complementarias. Lo razonable nos hace entrar en el mundo público pues nos faculta a elaborar términos justos de cooperación ${ }^{66}$

Vemos pues que se produce ya el primer gran quiebre con la TJ que aseguraba enfáticamente que si era factible derivar principios razonables de agentes racionales, es decir, derivar lo bueno (lo razonable) de lo justo (lo racional).

Rawls, se alejará así de la justicia formal kantiana (right) aunque va a continuar hablándonos de Justicia. Sin embargo, la justicia del LP, no

En su último libro Political Liberalism, (New York: Columbia University Press, 1993) edición en español : Liberalismo Politico (México : Fondo de Cultura Económica, 1995), resume todas las modificaciones a la TJ.

62 RawLs, John, LP, Ibid., p. 67.

63 Ibid., p. 69.

64 Lhwis Schaefrer, David, "Rawls Redux", en The Political Science Reviewer, Volume XXV, 1996, pp. 159-160. Vale decir que los dos poderes morales serían la racionalidad y la razonabilidad.

6.5 Rawls, John, LP, Ibid., p. 69.

66 Ibid., p. 71. 
será ya la justicia racional sino una justicia razonable o sustantiva que ahora sí tendrá un espacio claro y concreto dentro de la posición original.

La justicia como imparcialidad necesitará de la razonabilidad para que pueda ser percibida como una justicia cierta y real alejándose de la abstracción de los sujetos kantianos que prácticamente no podían ser considerados como seres de carne y hueso. ${ }^{67}$ Ahora bien, el apelar a la razonabilidad ponía en serios aprietos al profesor de Harvard pues si consideramos que la razonabilidad formaba parte de la posición original ¿cuál era el actual sentido del velo de ignorancia? aún más, ¿en base a qué criterios podía aseverar Rawls que los seres humanos eran mitad racionales y mitad razonables ?, ¿por qué tendríamos que seguir a Rawls y no a Hobbes, quien era el abanderado del modelo racionalista y que no creía que los seres humanos tuviesen un solo poro de razonabilidad?

Si bien, la razonabilidad no podía identificarse con el altruismo, no distaba mucho de éste y por eso el nuevo modelo dejaba la abstracción kantiana por cierto idealismo romántico, quizá más próximo a Hegel de lo que Rawls creyese. De hecho el LP, poseía una gran dosis de Sittlichkeit o eticidad:

«En una sociedad razonable, más sencillamente ilustrada en una sociedad de iguales en cuanto a los asuntos básicos, todos los ciudadanos tienen sus propios objetivos racionales que esperan favorecer, y todos están dispuestos a proponer términos justos que se espera razonablemente acepten los demás, de manera que todos puedan beneficiarse y mejorar, según lo que cada uno pueda lograr por si mismo. Esta sociedad razonable no es ni una sociedad de santos ni una sociedad de egocéntricos. Es como mucho, parte de nuestro mundo ordinario, un mundo al que no le atribuimos muchas virtudes, hasta que nos vemos fuera de él.»os

Si le diésemos a leer este párrafo a alguien que solamente conociese la TJ jamás podría imaginarse que tales ideas han sido escritas por la misma persona. Sin embargo, el cambio de Rawls es por demás evidente aunque él mismo considere que únicamente se tratan de aclaraciones a su libro original. ${ }^{69}$

\footnotetext{
67. Esto por la simple razón de que el velo de ignorancia al ocultar un sin fin de caracteres que describen e identifican a los seres humanos nos hacía perder también nuestro sentido de humanidad.

6. LP, Ibid.

6.) Ibid., p.l1.
} 
Empero, va a ser a través de su concepto del consenso traslapado (Overlapping Consensus) y en el renovado énfasis en sostener categóricamente que la nueva aproximación a la TJ debe ser una aproximación política y no metafísica o epistemológica donde se den los cambios más dramáticos y radicales y donde se apreciarán de mejor modo las nuevas contradicciones en el pensamiento rawlsiano.

Como lo mencionaba ya en un ensayo previo al LP, para Rawls «la filosofía como la búsqueda de la verdad de un orden metafísico y moral independiente no puede proveer una adecuada base para una concepción política de la justicia dentro de una sociedad democrática....trataremos entonces de dejar a un lado en la medida de lo posible las controversias filosóficas buscando la manera de huir de las prolongadas discusiones de los problemas filosóficos centrales. Así, en lo que yo he llamado un "constructivismo kantiano", tratamos de obviar el problema de la verdad y la controversia entre el realismo y el subjetivismo acerca del status de los valores morales y políticos. Esta forma de constructivismo ni afirma ni rechaza estas doctrinas. Al contrario, ésta reformula ideas de la tradición contractualista para lograr una concepción de objetividad y justificación fundada sobre un acuerdo público en los juicios. El propósito es un acuerdo librc, una reconciliación a través de la razón pública ${ }^{70}$.

En este sentido se podía entender que la teoría estaba restringida en su propósito a cubrir únicamente la «estructura básica» de la sociedad y su invocación a la política se dirigía a elaborar los valores compartidos de la libertad y de la igualdad que se supone se encontraban en ese espacio denominado por Rawls "consenso traslapado".

Rawls planteaba entonces no sólo la existencia de seres razonables dispuestos a honrar sus promesas y preocupados con los demás sino también un espacio que como una suerte de base o estructura común serviría para llegar a otro tipo de acuerdos. Conociendo que las sociedades contemporáneas son sociedades plurales y fraccionadas y existiendo temas filosóficos que podían ser tildados de irracionales e irrazonables ${ }^{71}$, esto es, temas incapaces de llegar a acuerdos definitivos como por ejemplo el aborto, la pornografía o la pena de muerte, se debería entender entonces que dichos temas deberían quedar fuera de la esfera legislativa. En definitiva «en una democracia constitucional la concepción pública de la justicia debiera presentarse, hasta donde esto es posible, como independiente de las doctrinas comprensivas religiosas, filosóficas y morales. $\gg^{72}$

70 Rawls, John, «Justice as Fairness : Political not Metaphysical», Ibid., p.194.

71 LP, Ibid., p. 146.

72 Ibid. 
Para Rawls dicho "consenso traslapado» se hallaría básicamente en el consenso constitucional en lo que él denomina «una estructura básica de una democracia constitucional moderna ${ }^{73}$; que llevaría por estandartes tanto al principio de la libertad como el de la igualdad repitiendo más o menos el mismo esquema propuesto por John Locke en el siglo XVII, «esto sería en esencia lo que constituiría el consenso traslapado». ${ }^{74}$

Rawls apela también a definir su nueva lectura de la TJ como anclada en un contexto y una cultura determinada, vale decir, que esta cultura como estamos viendo no sería otra que la cultura pública de las sociedades democráticas, empero como señalan sus críticos «en ninguna parte del LP (ni mucho menos en la TJ) Rawls se compromete en cualquier intento serio de explicar que significa "cultura», como se pueden identificar las ideas centrales a ella, o como es que ésta se forma y sostiene. $\gg^{75}$

En síntesis, Rawls sostiene ahora que su modelo ha dejado de ser un marco universal para pasar a ser exclusivamente un modelo made in America ${ }^{76}$ que únicamente puede tener vigencia y sentido en dicha comunidad. Sin embargo, salta a la vista las graves incongruencias del renovado planteamiento pues al pretenderse separar lo filosófico de lo político se nos aleja aún más de la justicia sustantiva (que se supone debería ir de la mano con la razonabilidad) en tanto que ésta queda desprovista de sus contenidos elementales como son los temas morales y filosóficos. Por ello como mencionábamos, la «sociedad bien ordenada» contemporánea no tendría por qué hacerse problemas con los asuntos más relevantes de la agenda política del mundo de hoy en tanto que para Rawls estos no serían exactamente problemas políticos (nos referimos por ejemplo al aborto, el racismo, etc.), sino más bien éticos. Así pues, lo que aparecía como un intento por superar las contradicciones formalistas de la $\mathrm{TJ}$ se convertían ahora en incongruencias más manifiestas pues seguían escamoteando la perspectiva axiológica (que tendría que incluir por fuerza a la metafísica y a la moral) y, lo que es más grave, se renunciaba expresamente a la ambición de contar con un modelo uni-

73 "Justice as Fairness: Political not Metaphysical», Ibid., p. 188.

74 "RAWIS REDUX", Ibid., p. 177.

$75 \quad$ Ibid., p. 167.

76 Aun cuando se advierta que tal "consenso traslapado» descansa más en las mentes de ciertos intelectuales norteamericanos antes que en la propia realidad.

«Rawls simplemente ha resumido en una peculiar y abstracta forma los dogmas fundamentales de la ideología que congenia más con la mayoría de los acadénicos norteamericanos en las últimas décadas."

"RAWLS REDUX", Ibid., p. 178. 
versal que pudiese servir para evitar los peligros y los conflictos del relativismo. Welcome Nibilism (bienvenido nihilismo) podría ser quizá el libro que faltase para concluir así la trilogía del senil profesor de Harvard y de su senil teoría de la Justicia.

\section{Conclusión}

Resulta por demás interesante añadir que el Profesor Rawls ha encarnado en los últimos años el paradigma de la filosofia liberal y en este sentido el fracaso de La teoria de la justicia hecha pública con los sucesivos artículos que culminaron con el liberalismo político sumados a las críticas aún más fundamentadas de su último libro deben servirnos como advertencia de que el modelo liberal y su justicia formal tienen serios problemas para poder constituir un instrumento útil e imitable.

La crisis valorativa que no afecta solo a los países postindustrializados sino que también la vivimos de manera descarnada en el Perú es simplemente un signo más de que los sistemas político-jurídicos (y en especial el llamado Estado de Derecho) tienen necesariamente que ser replanteados porque así como están ahora, si ni siquiera son capaces de servir a un país como los Estados Unidos de Norteamérica que en teoría debería de tener menos conflictos que nosotros, menos podría ser tomado como ejemplo por un país como el Perú en donde la sola idea del "consenso traslapado» sonaría peor que chiste de mal gusto.

Al mismo tiempo, pensamos que ya es hora de preguntarnos seriamente por el sentido que pudiese tener una teoría aún muy en boga en nuestra Facultad de Derecho; como la del «Law and Economics»; que como bien sabemos proviene justamente de esta misma matriz norteamericana y; más aún; cuando el mismísimo Guru del liberalismo anglosajón, el profesor John Rawls descarta ya de plano la utilización de la teoría de la elección racional como herramienta válida para construir una teoría de la Justicia. 